\title{
MOF-5 decorated hierarchical ZnO nanorod arrays and its photoluminescence
}

\author{
Yinmin Zhang, Ding Lan, Yuren Wang*, He Cao, Heng Jiang \\ Key Laboratory of Microgravity, Institute of Mechanics, Chinese Academy of Sciences, Beijing 100190, China
}

\section{A R T I C L E I N F O}

\section{Article history:}

Received 19 November 2010

Received in revised form

23 January 2011

Accepted 13 February 2011

Available online 17 February 2011

\begin{abstract}
A B S T R A C T
The strategy to manipulate nanoscale materials into well-organized hierarchical architectures is very important to both material synthesis and nanodevice applications. Here, nanoscale MOF-5 crystallites were successfully fabricated onto ordered hierarchical $\mathrm{ZnO}$ arrays based on aqueous chemical synthesis and molecule self-assembly technology guided room temperature diffusion method, which has the advantages of energy saving and simple operation. The structures and morphologies of the samples were performed by X-ray powder diffraction and field emission scanning electronic microscopy. The MOF-5 crystallites have good quality and bind well to the hexagonal-patterned $\mathrm{ZnO}$ arrays. The photoluminescence spectrum shows that the emission of hybrid MOF-5-ZnO films displays a blue shift in green emission and intensity reduction in UV emission. This ordered hybrid semiconductor material is expected to exploit the great potentiality in sensors, micro/nanodevices, and screen displays.
\end{abstract}

(c) 2011 Elsevier B.V. All rights reserved.

\section{Introduction}

As we know, zeolites and related siliceous materials have interesting properties compared with the other porous materials, namely highly regular pore structures and exceptionally high chemical and thermal stabilities. However, the range of control of functionality at molecular level still leaves a large margin for some important applications. Metal-organic frameworks (MOFs) whose skeletons constructed from inorganic metal ions and organic functional groups are a new class of porous materials. They are hybrid inorganic-organic solid-state compounds with zeolite-like structures, yet transgressing the limitations of zeolites in terms of materials chemistry. That is to say, the pore size, morphology, and surface functionality of MOF materials can be easily tuned upon selection of different metal ions and organic molecules, which is the superiority compared with conventional porous materials. Therefore, that would make it possible to design MOF materials with desired properties. Under the worldwide background of capturing and storing carbon and exploiting clean energy based hydrogen, a large number of researches on MOFs are directed to exploit MOFs with super-high specific surface area $[1,2]$. For this reason, one of the most significant applications of MOFs is gas storage [3-7]. The idea of tuning the properties also makes the extensive applications in separation $[8,9]$, catalysis [10,11], and drug delivery [12,13].

\footnotetext{
* Corresponding author. Tel.: +86 01082544091 ; fax: +86 01082544096.

E-mail address: yurenwang@imech.ac.cn (Y. Wang).
}

As a member of the MOF- $n$ materials [14], MOF-5, also known as isoreticular metal organic framework-1 (IRMOF-1), can be traced back to the end of 1990s [15,16] and shows high hydrogen-storage capacities. Presently the study of MOFs mainly focused on powders. Indeed, various potential applications such as micro-optics and photonic devices, microelectronics, functional and protective coatings, sensors, biomaterials, and microfluidic devices are associated with the morphology of a membrane on certain substrate [17]. Till now, very few studies of MOF films have been reported compared with that of MOF powders. Hermes et al. [18] have demonstrated selective nucleation and growth of MOF thin films on patterned carboxylate-terminated selfassembled monolayers on Au (1 111 ). While Biemmi et al. [19] prepared the porous framework HKUST-1 on various functionalized self-assembled monolayers via oriented growth.

To direct the nucleation and growth of MOFs on substrates, self-assembled monolayer (SAM) technology has been extensively used as a link between MOFs and substrates [18,20,21]. What deserves to be mentioned the most is that zinc oxide ( $\mathrm{ZnO})$, as an important semiconductor materials, has been extensively studied. Dot-like, rod-like, and flower-like structures have been fabricated via various methods [22-24]. And it can be widely used in lightemitting diode [25], ultraviolet laser [26], solar cells [27], and piezoelectric nanogenerators [28]. Recently, several studies have shown that thiol molecules can adsorb on $\mathrm{ZnO}$ surfaces and nanoparticles [29-31]. However, the combination of MOF films and ordered $\mathrm{ZnO}$ arrays using SAM had not been reported so far. In this paper, we report the formation of MOF-5 thin films on ordered hierarchical $\mathrm{ZnO}$ arrays via a modified slow diffusion 
approach. The crystalline MOF-5 has small sizes. Ordered hierarchical $\mathrm{ZnO}$ arrays were prepared through the aqueous chemical synthesis method. Utilizing molecule self-assembly technology, the MOF-5 crystallites were perfectly combined with the patterned ZnO substrate. Our previous work [32-34] focuses on the morphology control of $\mathrm{ZnO}$ nanomaterials, which provides a sound basis for surface modification on $\mathrm{ZnO}$. Considering the MOF-5 possesses the characteristic of semiconductor, this composite-semiconductor membrane would be beneficial for potential applications in chemical sensing, photocatalysis, and other optoelectronic devices.

\section{Experimental sections}

Zinc nitrate $\left(\mathrm{Zn}\left(\mathrm{NO}_{3}\right)_{2} \cdot 6 \mathrm{H}_{2} \mathrm{O}\right)$, hexamethylenetetramine $\left(\mathrm{C}_{6} \mathrm{H}_{12} \mathrm{~N}_{4}\right), 1,4$-benzenedicarboxylic acid $\left(\mathrm{H}_{2} \mathrm{BDC}\right)$, N,N'-dimethylformamide (DMF), and triethylamine (TEA) were of analytical reagent grade from commercial sources and were used without further purification. Polystyrene sphere (PS) suspensions were bought from Thermo Fisher Scientific Inc. The average diameter of PS is $1000 \mathrm{~nm}$ and the solids mass fraction in the suspensions is $10 \%$ by weight.

The $\mathrm{ZnO}$ nanocrystals were prepared according to Meulenkamp's method [35], while the ZnO seeds layer was prepared on the glass substrate (microscope slide, Sail brand, Cat. No. 7101) by the dip coating method. The substrate was annealed at $450{ }^{\circ} \mathrm{C}$ to burn out the residual organic materials and well-crystallized $\mathrm{ZnO}$ film was obtained.

Large-scale PS monolayer colloidal crystals $\left(>1.5 \mathrm{~cm}^{2}\right.$ in area) were prepared by an air-liquid-solid interface self-assembly method [36]. The PS monolayer templates were treated at $90{ }^{\circ} \mathrm{C}$ for $0.25 \mathrm{~h}$ in order to enhance the adhesion between PS particles and $\mathrm{ZnO}$ seeds layer.

Bowl-rod hierarchical $\mathrm{ZnO}$ structures were fabricated by aqueous chemical synthesis with assistance of PS monolayer templates, as schematically illustrated in Fig. 1. The growth experiment was carried out in a sealed Teflon vessel, which contained $15 \mathrm{~mL}$ equimolar (typically, $0.05 \mathrm{M}$ was used) aqueous solution of $\mathrm{Zn}\left(\mathrm{NO}_{3}\right)_{2}$ and $\mathrm{C}_{6} \mathrm{H}_{12} \mathrm{~N}_{4}$. The whole growth process lasted for $2 \mathrm{~h}$ at the temperature of $90{ }^{\circ} \mathrm{C}$. Then the sample was washed with deionized water and dried under nitrogen gas stream, following to be heated at $450{ }^{\circ} \mathrm{C}$ for $1 \mathrm{~h}$ in the atmosphere to burn out the PS.

The bowl-rod-like hierarchical $\mathrm{ZnO}$ arrays were immersed in $50 \mathrm{~mL}$ of $1 \mathrm{mM}$ 11-mercaptoundecanoic acid ethanolic solution for the thiol molecule to self-assemble on the $\mathrm{ZnO}$ surfaces. It was carried out in atmosphere and lasted at least $12 \mathrm{~h}$, after which the

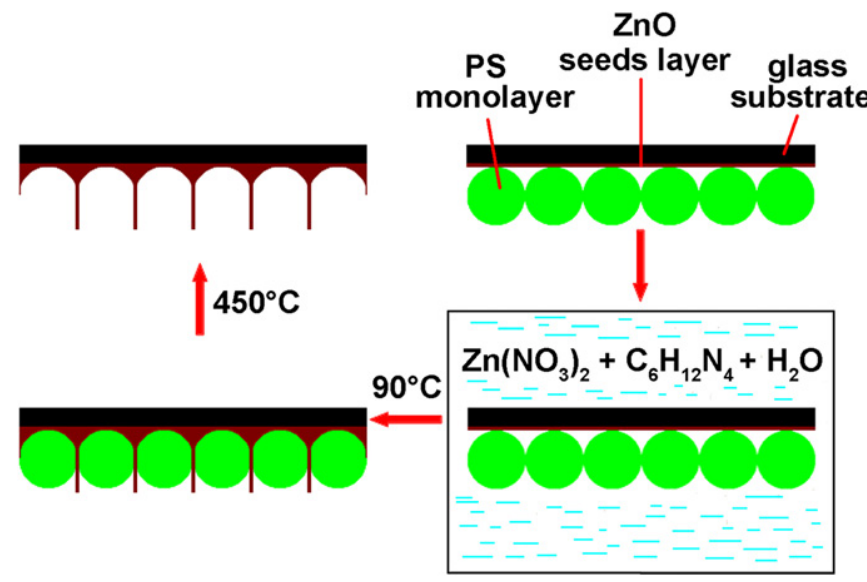

Fig. 1. Schematic illustration of the synthesis process of $\mathrm{ZnO}$ bowl-rod hierarchical structures. thiol-capped $\mathrm{ZnO}$ arrays were rinsed with ethanol and dried under $\mathrm{N}_{2}$ stream.

The procedure for synthesizing MOF-5 given in the literature $[37,38]$ was modified. The DMF solution containing $\mathrm{Zn}\left(\mathrm{NO}_{3}\right)_{2} \cdot 6 \mathrm{H}_{2} \mathrm{O}, \mathrm{H}_{2} \mathrm{BDC}$ was placed in a small beaker. Ethanolic solution of TEA was placed in a larger beaker. The small beaker was placed in the center of the larger beaker. The whole system was covered with seal membrane and kept under $50{ }^{\circ} \mathrm{C}$ for $12 \mathrm{~h}$. The white precipitate in small beaker was filtered and transparent filtrate was obtained. The SAM-modified $\mathrm{ZnO}$ arrays were placed upside-down on a clean glass-support in the filtrate. Then, the small beaker containing filtrate was placed in the larger one again. The whole system was sealed and kept under $25^{\circ} \mathrm{C}$ for $48 \mathrm{~h}$. After the synthesis, the $\mathrm{ZnO}$ arrays were washed with DMF and ethanol and then dried for $3 \mathrm{~h}$ at $100{ }^{\circ} \mathrm{C}$.

The shape and crystal structure of the resulting sample were investigated by field emission scanning electron microscopy (FESEM, LEO1530) and X-ray diffraction (XRD, Rigaku D/MAXRB). X-ray photoelectron spectroscopy (XPS) and photoluminescence (PL) spectra were measured by PHI Quantera SXM system and SPEX-1403 laser Raman spectrometer.

\section{Results and disscussion}

Fig. 2 shows a representative SEM image of bowl-rod-like hierarchical $\mathrm{ZnO}$ arrays. The whole $\mathrm{ZnO}$ arrays occupy a large area and exhibit iridescent color under sunlight at different angles. The arrays possess a primary structure of hexagonal microbowls and a secondary structure of nanorods. The diameter of the top edge of the microbowls is about $1 \mu \mathrm{m}$. The diameter of the nanorods varies from 50 to $200 \mathrm{~nm}$ and their length is about $0.7 \mu \mathrm{m}$ (Fig. 2, inset). As is known, $\mathrm{ZnO}$ is a kind of polar crystal with the polar axis along the $c$-axis ( $<001>$ ). Polar faces with surface dipoles are thermodynamically less stable than non-polar faces and tend to grow more rapidly. Laudise et al. [39] reported that the higher the growth rate, the quicker the disappearance of the plane. Therefore, the polar $\left(\begin{array}{lll}0 & 0 & 1\end{array}\right)$ faces are the most rapid-growth-rate planes as compared to other growth facets. That is to say, ZnO grows fast along the [ $\left[\begin{array}{lll}0 & 0 & 1\end{array}\right]$ direction. Since $\mathrm{ZnO}$ crystal growth happened in a small confined space provided by the PS monolayer template and the substrate, bowl-rod-like hierarchical $\mathrm{ZnO}$ structures were obtained. When $\mathrm{ZnO}$ crystallites grew in the region shadowed by PS, they had to grow along the outline of the PS due to the spatial confinement, and then formed the bowl-like structures. However, the region located among every three PSs, not shadowed by PS, is open to air. The $\mathrm{ZnO}$ crystallites had

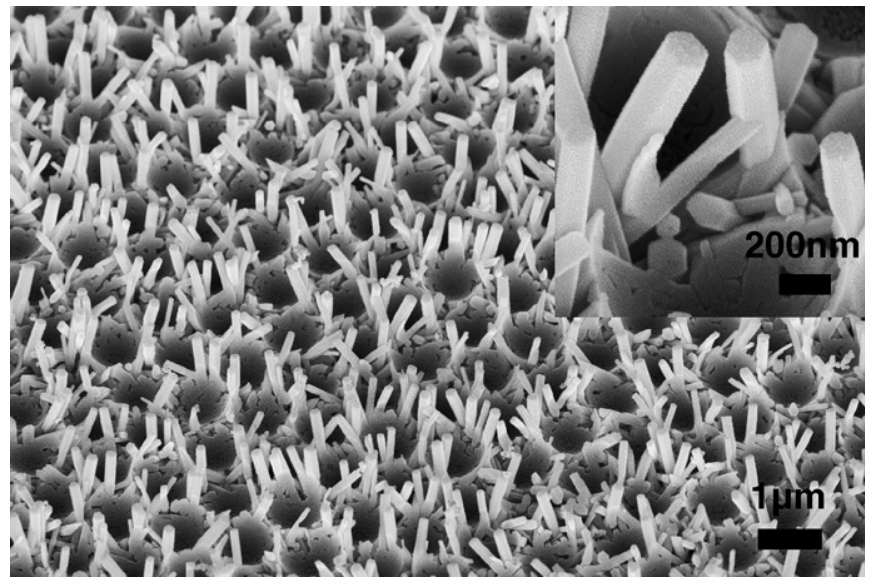

Fig. 2. SEM image of a typical $\mathrm{ZnO}$ arrays (tilted $45^{\circ}$ ), the inset shows the corresponding high-magnification SEM image. 
chance to grow further and form the rod-like structures. Fig. 3 shows the XRD pattern of the hierarchical arrays. All diffraction peaks can be identified as diffractions from hexagonal wurtzite $\mathrm{ZnO}$. It is demonstrated that the hierarchical $\mathrm{ZnO}$ arrays preserved polycrystalline structure. The enhanced $\left(\begin{array}{lll}0 & 0 & 2\end{array}\right)$ peak indicated that a strongly oriented structure was formed along the $<001>$ crystalline direction in the as-grown arrays.

Fig. 4 presents the thin MOF-5 films on ordered hierarchical $\mathrm{ZnO}$ arrays. It can be seen that the synthesized MOF- 5 crystallites have smaller sizes (less than $100 \mathrm{~nm}$ ) compared with the

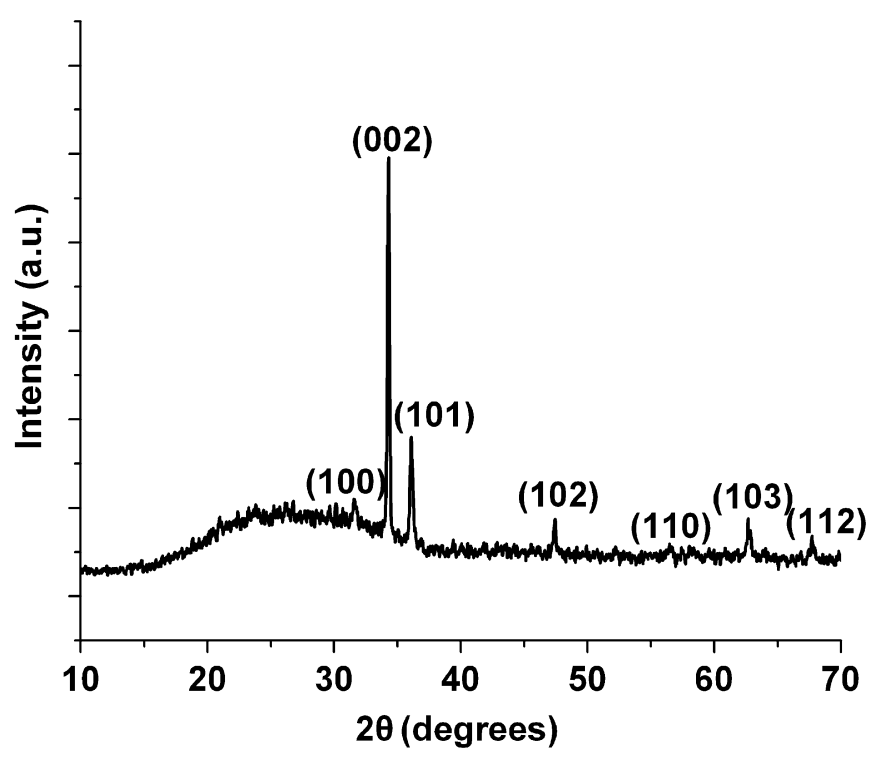

Fig. 3. XRD pattern of $\mathrm{ZnO}$ hierarchical arrays. traditional diffusion method [38]. This is because the initially formed white precipitate in the small beaker was filtered, which can effectively avoid the emergence of Ostwald ripening in the process of crystal growth. When 11-mercaptoundecanoic acid was dissolved in ethanol, the exposed end groups were both - $\mathrm{SH}$ and $-\mathrm{COOH}$. It should be noted that the bond energy of $\mathrm{Zn}-\mathrm{S}$ $(205 \mathrm{~kJ} / \mathrm{mol})$ is higher than that of $\mathrm{Zn}-\mathrm{O}(159 \mathrm{~kJ} / \mathrm{mol})$ [40]. Therefore, $-\mathrm{SH}$ end groups would be easier to anchor the $\mathrm{ZnO}$ surface forming - $\mathrm{COOH}$-terminated SAM on the entire $\mathrm{ZnO}$ surface. A comparison of the XPS spectra carried out for the bare $\mathrm{ZnO}$ and SAM-modified $\mathrm{ZnO}$ is shown in Fig. 5a. The peak of SAMmodified $\mathrm{ZnO}$ was shifted, which implied that some of the $\mathrm{Zn}-\mathrm{O}$ bonds had been transferred into $\mathrm{Zn}-\mathrm{S}$ bonds. In Fig. $5 \mathrm{~b}$, the $\mathrm{S} 2 \mathrm{p}$ peak was observed in the spectrum of SAM-modified $\mathrm{ZnO}$. The $\mathrm{S}$ $2 \mathrm{p}$ peak can be resolved into three components of binding energies of $161.8,162.9,164.2 \mathrm{eV}$, which are bound up with

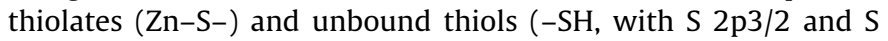
$2 \mathrm{p} 1 / 2$ components), respectively. These results fully illustrated that SAM had been effectively formed on ZnO surface. Carboxyl, as an important organic functional group, has been proved that it is crucial to involve in crystal growth [19,41]. Here, -COOHterminated SAM enables coordination of the zinc ions or secondary building units (SBUs) [42] from the solution to the ZnO surface. The attached zinc centers or SBUs will be subsequently coordinated by the organic ligands $\left(\mathrm{H}_{2} \mathrm{BDC}\right)$ present in the solution. Then the crystal growth of the desired MOF-5 occurs with the crystals being directly attached to the $\mathrm{ZnO}$ surface. From Fig. 4b and the inset of Fig. 4a, we can see that both $\mathrm{ZnO}$ microbowls and $\mathrm{ZnO}$ nanorods are well encapsulated by MOF-5 crystallites. The hexagonal pattern of the films can also be clearly seen. The diameter of the nanorods is about $100 \sim 250 \mathrm{~nm}$ and their length is approximately equal to that of nanorods before encapsulation. What we should pay attention to is that the PS

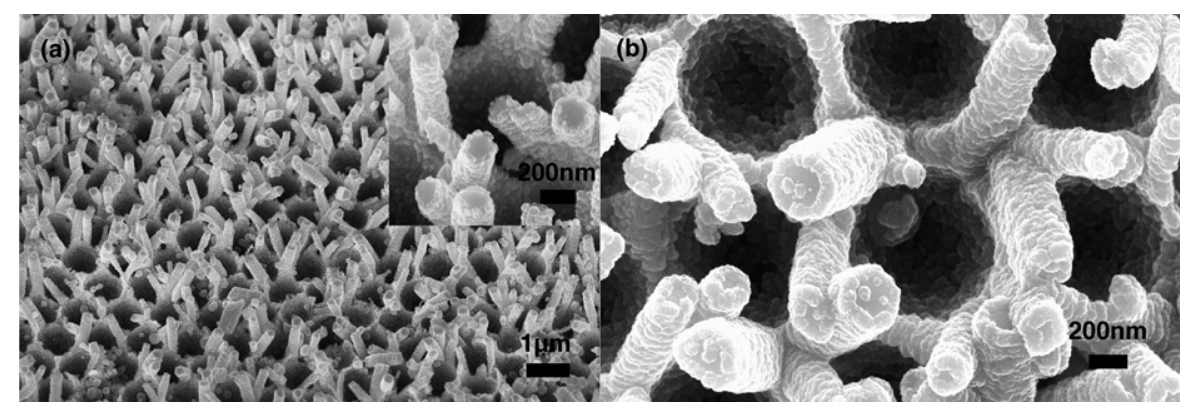

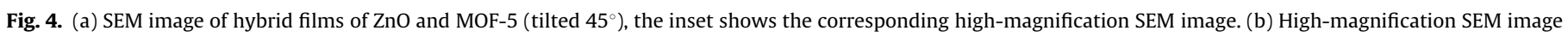
of the hybrid films (without tilt).

a

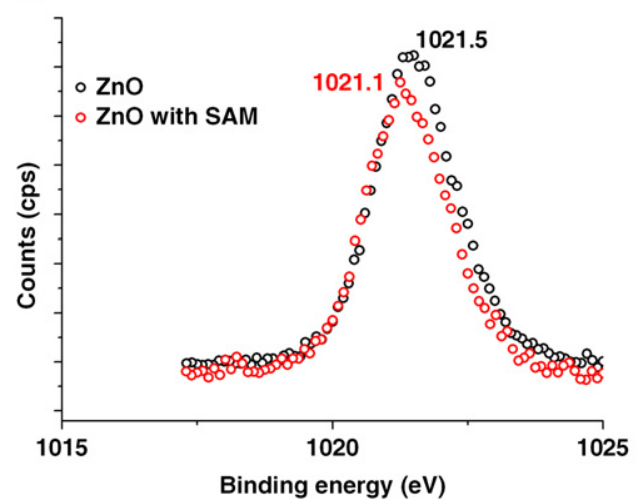

b

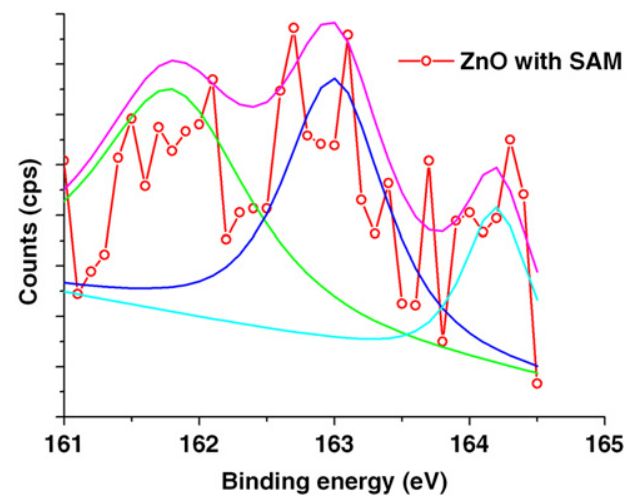

Fig. 5. (a) Zn 2p3/2 XPS spectra of ZnO hierarchical arrays with and without SAM. (b) S 2p XPS spectra of ZnO hierarchical arrays with SAM. 
monolayer template not only enables formation of ordered hybrid structures, but also leaves space for the MOF-5 crystallites growing on $\mathrm{ZnO}$ surface. The $\mathrm{ZnO}$ nanorods arrays are relatively sparse with a density varying from $2.3 \times 10^{8}$ to $1.2 \times 10^{9} \mathrm{~cm}^{-2}$, and the distance between nanorod bundles is large enough to let growth solution readily diffuse into the space. Without PS template, the $\mathrm{ZnO}$ arrays are crowded nanorods structures, leaving no room for the growth of MOF-5 except the top $\mathrm{ZnO}$ surface.

Because the thickness of the MOF-5 on ZnO arrays is too less, it is unable to directly determine the crystal structure of MOF- 5 using XRD. A feasible alternative is to choose the MOF-5 crystallites in liquid phase for indirect determination of the crystal structure. Fig. 6 shows the corresponding XRD pattern. The typical pattern agrees with the experimental results shown by Huang et al. [37] and Saha et al. [43]. It means that the crystal structure of the synthesized crystallites in liquid phase fits well with that of MOF-5.

Both MOFs and $\mathrm{ZnO}$ are important photoluminescent materials. Therefore, it is necessary to investigate their luminescent

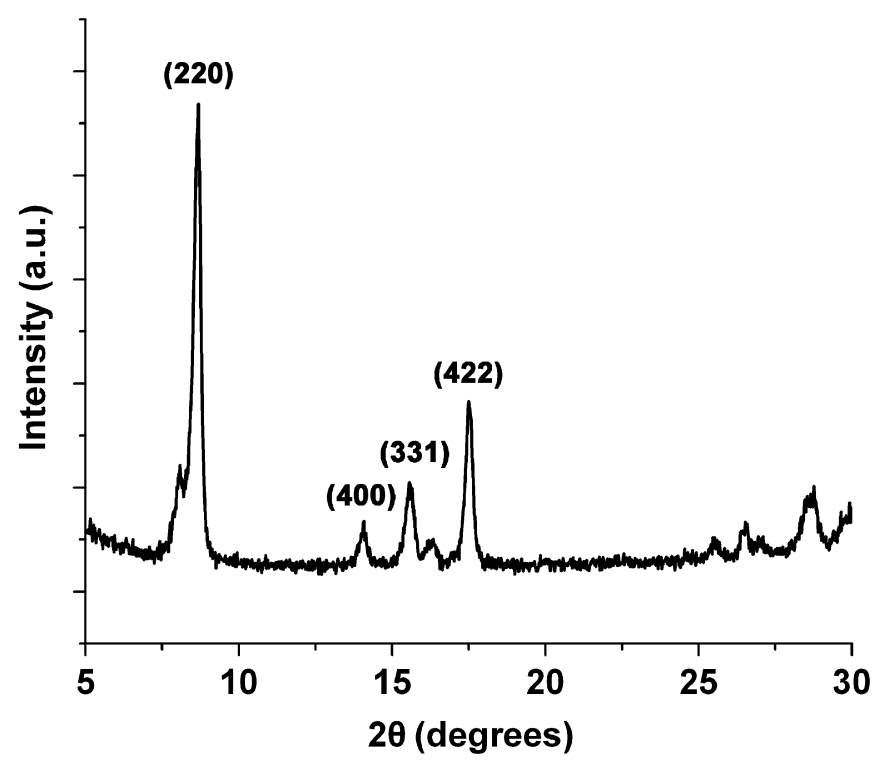

Fig. 6. XRD pattern of MOF-5 crystallites formed in liquid phase.

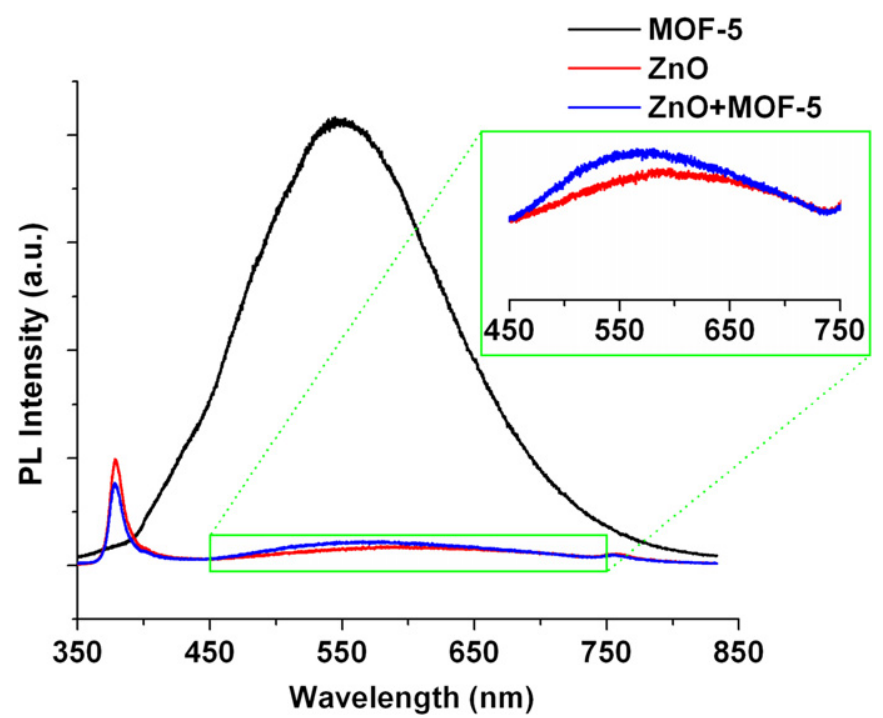

Fig. 7. Room temperature PL spectra of MOF-5 crystallites, hierarchical $\mathrm{ZnO}$ arrays and hybrid MOF-5-ZnO films, enlargement of the region between 450 and $750 \mathrm{~nm}$ is shown as the inset. properties. Fig. 7 shows the PL spectra of MOF-5 crystallites, hierarchical $\mathrm{ZnO}$ arrays, and MOF-5 films on $\mathrm{ZnO}$ arrays. The MOF-5 crystallites exhibit a significant PL with a maximum at $550 \mathrm{~nm}$, as indicated by the black solid curve. The PL spectrum of hierarchical $\mathrm{ZnO}$ has both ultraviolet (UV) and green emissions, of which the origins can be attributed to band edge exciton transition and the deep level transition from oxygen vacancies, respectively [44-47]. The low efficient green emission is characterized by a broad band centered at $600 \mathrm{~nm}$. As for the hybrid films of MOF-5 and $\mathrm{ZnO}$, UV and green emissions are also observed. Interestingly, the intensity of the UV emission decreases compared to that of pure hierarchical $\mathrm{ZnO}$, and a blue shift of about $50 \mathrm{~nm}$ is observed in the green emission. The blue shift and amplitude reduction of UV emission are usually thought to originate from fluorescence resonance energy transfer between $\mathrm{ZnO}$ and MOF-5. It is indicated that the MOF-5 thin films well attach to hierarchical $\mathrm{ZnO}$ arrays and effectively affect the $\mathrm{ZnO}$ luminescent behavior. As for $\mathrm{ZnO}$, the $380 \mathrm{~nm}$ emission is more efficiently generated by exciting it with $325 \mathrm{~nm}$ photons. Furthermore, the $380 \mathrm{~nm}$ photons excite the MOF-5 thin films, which results in the reduced intensity of ZnO UV emission and the enhanced green emission. The observed enhancement reveals respectable energy transfer from $\mathrm{ZnO}$, acting as a donor, to MOF-5, where the electron-hole recombination occurs. There is another near-infrared (NIR) emission at $760 \mathrm{~nm}$. The NIR emission is mostly attributed to excess oxygen [48], however, zinc interstitials are also proposed to explain the origin of NIR emission [49]. Yet anyhow, the MOF-5 films hardly affect the NIR emission of the hierarchical $\mathrm{ZnO}$, which indirectly explains that energy transfer accounts for the change in UV and green emission in a large part. These findings open up interesting optical applications of MOF-5. It has considerable advantages in terms of potential applications in optoelectronic devices and might be used as spectral-conversion layer for thin-film harvesting solar cells.

\section{Conclusion}

We have demonstrated the growth of MOF-5 thin films on ordered $\mathrm{ZnO}$ arrays using a modified slow diffusion approach combined with molecule self-assembly technology. The as-prepared MOF- 5 crystallites have small sizes and good quality. These small crystallites grow well against the surface profile of the patterned $\mathrm{ZnO}$ arrays and they also display the hexagonal arrangement. The PL spectrum of MOF-5-ZnO hybrid films shows a blue shift in green emission and intensity reduction in UV emission compared with that of pure hierarchical $\mathrm{ZnO}$ arrays. This facile and effective method might be promising to implement the fabrication of high-performance devices as an excellent alternative.

\section{Acknowledgment}

This study was supported by the National Basic Research Program of China (973 Program, no. 2011CB710901), the National Natural Science Foundation of China (Grant no. 10832011), and the Knowledge Innovation Program of the Chinese Academy of Sciences (Grant no. KJCX2-YW-L08).

\section{References}

[1] H.K. Chae, D.Y. Siberio-Pérez, J. Kim, Y. Go, M. Eddaoudi, A.J. Matzger, M. O'Keeffe, O.M. Yaghi, Nature 427 (2004) 523.

[2] G. Férey, C. Mellot-Draznieks, C. Serre, F. Millange, J. Dutour, S. Surblé, I. Margiolaki, Science 309 (2005) 2040. 
[3] M.D. Ward, Science 300 (2003) 1104.

[4] G. Férey, M. Latroche, C. Serre, F. Millange, T. Loiseau, A. Percheron-Guégan, Chem. Commun. (2003) 2976.

[5] D.J. Collins, H.C. Zhou, J. Mater. Chem. 17 (2007) 3154.

[6] A.G. Wong-Foy, A.J. Matzger, O.M. Yaghi, J. Am. Chem. Soc. 128 (2006) 3494.

[7] M. Dincǎ, J.R. Long, Angew. Chem., Int. Ed. 47 (2008) 6766.

[8] Q.M. Wang, D.M. Shen, M. Bülow, M.L. Lau, S.G. Deng, F.R. Fitch, N.O. Lemcoff, J. Semanscin, Microporous Mesoporous Mater. 55 (2002) 217.

[9] T.K. Maji, K. Uemura, H.C. Chang, R. Matsuda, S. Kitagawa, Angew. Chem., Int. Ed. 43 (2004) 3269.

[10] J.S. Seo, D. Whang, H. Lee, S.I. Jun, J. Oh, Y.J. Jeon, K. Kim, Nature 404 (2000) 982.

[11] R.Q. Zou, H. Sakurai, S. Han, R.Q. Zhong, Q. Xu, J. Am. Chem. Soc. 129 (2007) 8402.

[12] P. Horcajada, C. Serre, M. Vallet-Regí, M. Sebban, F. Taulelle, G. Férey, Angew. Chem., Int. Ed. 45 (2006) 5974.

[13] P. Horcajada, C. Serre, G. Maurin, N.A. Ramsahye, F. Balas, M. Vallet-Regí, M. Sebban, F. Taulelle, G. Férey, J. Am. Chem. Soc. 130 (2008) 6774.

[14] M. Eddaoudi, H.L. Li, O.M. Yaghi, J. Am. Chem. Soc. 122 (2000) 1391.

[15] O.M. Yaghi, C.E. Davis, G.M. Li, H.L. Li, J. Am. Chem. Soc. 119 (1997) 2861.

[16] H.L. Li, M. Eddaoudi, M. O’Keeffe, O.M. Yaghi, Nature 402 (1999) 276.

[17] C. Sanchez, C. Boissière, D. Grosso, C. Laberty, L. Nicole, Chem. Mater. 20 (2008) 682 .

[18] S. Hermes, F. Schröder, R. Chelmowski, C. Wöll, R.A. Fischer, J. Am. Chem. Soc. 127 (2005) 13744.

[19] E. Biemmi, C. Scherb, T. Bein, J. Am. Chem. Soc. 129 (2007) 8054.

[20] D. Zacher, A. Baunemann, S. Hermes, R.A. Fischer, J. Mater. Chem. 17 (2007) 2785.

[21] E. Biemmi, A. Darga, N. Stock, T. Bein, Microporous Mesoporous Mater. 114 (2008) 380.

[22] S.W. Kim, S. Fujita, S. Fujita, Appl. Phys. Lett. 81 (2002) 5036.

[23] L. Vayssieres, Adv. Mater. 15 (2003) 464.

[24] H. Zhang, D.R. Yang, X.Y. Ma, Y.J. Ji, J. Xu, D.L. Que, Nanotechnology 15 (2004) 622.

[25] R. Könenkamp, Robert C. Word, C. Schlegel, Appl. Phys. Lett. 85 (2004) 6004

[26] M.H. Huang, S. Mao, H. Feick, H.Q. Yan, Y.Y. Wu, H. Kind, E. Weber, R. Russo, P.D. Yang, Science 292 (2001) 1897.
[27] G. Gordillo, Surf. Rev. Lett. 9 (2002) 1675.

[28] Z.L. Wang, J.H. Song, Science 312 (2006) 242.

[29] S.Z. Deng, H.M. Fan, M. Wang, M.R. Zheng, J.B. Yi, R.Q. Wu, H.R. Tan, C.H. Sow, J. Ding, Y.P. Feng, K.P. Loh, ACS Nano 4 (2010) 495.

[30] J. Hedberg, C. Leygraf, K. Cimatu, S. Baldelli, J. Phys. Chem. C 111 (2007) 17587.

[31] P.W. Sadik, S.J. Pearton, D.P. Norton, E. Lambers, F. Ren, J. Appl. Phys. 101 (2007) 104514.

[32] Y.M. Zhang, D. Lan, Y.R. Wang, H. Cao, Y.P. Zhao, J. Colloid Interface Sci. 351 (2010) 288.

[33] D. Lan, Y.M. Zhang, Y.R. Wang, Appl. Surf. Sci. 254 (2008) 5849.

[34] D. Lan, Y.R. Wang, X.L. Du, Z.X. Mei, Q.K. Xue, K. Wang, X.D. Han, Z. Zhang, Cryst. Growth Des. 8 (2008) 2912.

[35] E.A. Meulenkamp, J. Phys. Chem. B 102 (1998) 5566.

[36] A. Kosiorek, W. Kandulski, P. Chudzinski, K. Kempa, M. Giersig, Nano Lett. 4 (2004) 1359

[37] L.M. Huang, H.T. Wang, J.X. Chen, Z.B. Wang, J.Y. Sun, D.Y. Zhao, Y.S. Yan, Microporous Mesoporous Mater. 58 (2003) 105.

[38] B. Panella, M. Hirscher, Adv. Mater. 17 (2005) 538.

[39] R.A. Laudise, A.A. Ballman, J. Phys. Chem. 64 (1960) 688.

[40] D.R. Lide, Handbook of Chemistry and Physics, 84th ed., CRC Press, Gaithersburg, MD, USA, 2004 Section 9, pp. 56.

[41] M. Munuera, O. Shekhah, H. Wang, C. Wöll, C. Ocal, Phys. Chem. Chem. Phys. 10 (2008) 7257.

[42] J.L.C. Rowsell, O.M. Yaghi, Microporous Mesoporous Mater. 73 (2004) 3.

[43] D. Saha, S.G. Deng, Z.G. Yang, J. Porous Mater. 16 (2009) 141.

[44] Z.K. Tang, G.K.L. Wong, P. Yu, M. Kawasaki, A. Ohtomo, H. Koinuma, Y. Segawa, Appl. Phys. Lett. 72 (1998) 3270.

[45] S. Cho, J. Ma, Y. Kim, Y. Sun, G.K.L. Wong, J.B. Ketterson, Appl. Phys. Lett. 75 (1999) 2761.

[46] K. Vanheusden, W.L. Warren, C.H. Seager, D.R. Tallant, J.A. Voigt, B.E. Gnade, J. Appl. Phys. 79 (1996) 7983.

[47] H.S. Kang, J.S. Kang, J.W. Kim, S.Y. Lee, J. Appl. Phys. 95 (2004) 1246.

[48] M. Koyano, P. QuocBao, L.T. ThanhBinh, L. HongHa, N. NgocLong, S. Katayama, Phys. Status Solidi A 193 (2002) 125.

[49] A.B. Djurišić, Y.H. Leung, Small 2 (2006) 944. 